\title{
Burden of non-communicable diseases attributable to dietary risks in Brazil, 1990-2019: an analysis of the Global Burden of Disease Study 2019
}

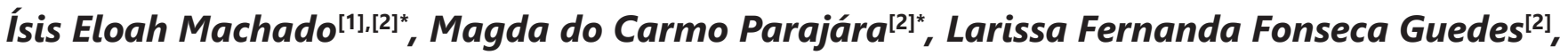 \\ Adriana Lúcia Meireles ${ }^{[2],[3], ~ M a r i a n a ~ C a r v a l h o ~ d e ~ M e n e z e s ~}{ }^{[2],[3],}$ \\ Mariana Santos Felisbino-Mendes ${ }^{[4]}$, Eliseu Verly-Junior ${ }^{[5]}$ and Deborah Carvalho Malta ${ }^{[4]}$
}

\begin{abstract}
[1]. Universidade Federal de Ouro Preto, Departamento de Medicina de Família, Saúde Mental e Coletiva, Ouro Preto, MG, Brasil.
[2]. Universidade Federal de Ouro Preto, Programa de Pós-Graduação em Saúde e Nutrição, Ouro Preto, MG, Brasil.

[3]. Universidade Federal de Ouro Preto, Departamento de Nutrição Clínica e Social, Ouro Preto, MG, Brasil.

[4]. Universidade Federal de Minas Gerais, Programa de Pós-Graduação em Enfermagem, Belo Horizonte, MG, Brasil.

[5]. Universidade do Estado do Rio de Janeiro, Instituto de Medicina Social, Departamento de Epidemiologia, Rio de Janeiro, RJ, Brasil.
\end{abstract}

\begin{abstract}
Introduction: An unhealthy diet is a modifiable risk factor for non-communicable diseases (NCDs), one of the most important public health problems in Brazil. This study aimed to analyze the burden of NCDs attributable to dietary risks in Brazil between 1990-2019. Methods: Secondary data from the Global Burden of Disease Study were used to estimate the burden attributable to fifteen dietary risks in Brazil. The main sources of data for Brazil were national surveys and international databases. A comparative risk assessment was used to obtain the population attributable fraction. We described the intake of each dietary risk and the distribution of number and rates of deaths and Disability-adjusted life years (DALYs) attributable to diet by sex, age, state, and year from 1990-2019. Results: Cardiovascular diseases, diabetes mellitus, and neoplasms were the main NCDs attributable to an unhealthy diet. Age-standardized mortality and DALYs rates attributable to unhealthy diet decreased between 1990-2019 (-51.5\% and -48.8, respectively). Diet high in red meat and sodium, and low in whole grains were the three main risk factors contributing to the burden of NCDs both in 1990 and 2019. The burden of NCDs was higher among males in the middle-aged population (around 50 years), as well as in the states of Maranhão, Rio de Janeiro, and Alagoas. Conclusions: The present study found a suboptimum diet among the Brazilian population. The major contributors to this burden were diet high in red meat and sodium and low in whole grains. This study supports priorities in public policies on food and nutrition to reduce the burden of NCDs.
\end{abstract}

Keywords: Nutritional epidemiology. Diet, food, and nutrition. Global Burden of Disease. Mortality. Disability-adjusted life years. Risk factors.

\section{INTRODUCTION}

Non-communicable diseases (NCDs) configure a huge public health problem ${ }^{1,2}$, with diabetes mellitus, cardiovascular diseases (CVDs), neoplasms, and chronic respiratory diseases being responsible for approximately $74 \%$ deaths worldwide ${ }^{2,3}$. Data from the Global Burden of Disease (GBD) study for Brazil have shown that the proportional mortality due to NCDs in 2017 corresponded to $75.9 \%$, while the proportion of premature deaths due to this disease group was $28 \%{ }^{4}$.

\footnotetext{
*These authors contributed equally to the work.

Corresponding author: Prof. Isis Eloah Machado.

e-mail: isiseloah@gmail.com

(D) https://orcid.org/0000-0002-4678-2074

Received 3 May 2021

Accepted 18 June 2021
}

As NCDs result in premature deaths and provide a high degree of limitation and inability to perform daily activities, this burden leads to a loss in the quality of life for individuals and families, causes an overload on health systems, and has a negative impact on the country's economy. It is important to emphasize that, although NCDs affect all socioeconomic strata, the disease burden falls more intensely on low- and middle-income countries, especially among those individuals belonging to vulnerable groups, with low education and lower income levels ${ }^{1,5,6}$.

Among the main risk behaviors related to NCDs morbidity and mortality, four modifiable risk factors stand out: inadequate diet, insufficient physical activity, tobacco use, and harmful consumption of alcoholic beverages ${ }^{1}$. Regarding the dietary pattern of the Brazilian population, in recent decades, an increase has been observed in ultra-processed food consumption and a decrease in the 
consumption of fresh foods, resulting in inadequate and, in general, highly energy-dense and nutrient-poor diets ${ }^{7}$. Low- and middleincome countries, such as Brazil, where there are vulnerabilities in food access, have been experiencing a coexistence of malnutrition with undernutrition, overweight, obesity, and $\mathrm{NCDs}^{8}$.

The monitoring of NCDs and their risk factors to better understand their trends have been considered a public health priority and an important action for the development and implementation of effective public policies in Brazil ${ }^{9,10}$. Considering the present pandemic scenario, it is already well-known that the severity and mortality of COVID-19 has significantly increased in people with NCDs. Moreover, the ability of countries to address and respond to NCDs has been impacted ${ }^{11}$. Therefore, tackling the major risk factors for NCDs, such as diet, is a constant concern.

Thus, this study aims to analyze the burden of NCDs attributable to dietary risks in Brazil, regarding the deaths and Disabilityadjusted life years (DALYs) between 1990 and 2019, according to estimates from the GBD 2019 study.

\section{METHODS}

This study used secondary data publicly available in GBD study 2019, developed by the Institute for Health Metrics and Evaluation (IHME). The data were extracted in February 2021 through the GBD Results Tool (http://ghdx.healthdata.org/gbd-results-tool) for Brazil and its 27 states.

We analyzed the 15 dietary risks proposed by the GBD 2019 according to sufficient and available data to estimate risk factors exposure $^{12}$. Hence, the dietary risks evaluated were diet low in fruits, vegetables, legumes, whole grains, nuts and seeds, milk, fiber, calcium, seafood omega-3 fatty acids, and polyunsaturated fatty acids (PUFA), and diet high in red meat, processed meat, sugar sweetened beverages (SSBs), trans fatty acids (TFA), and sodium ${ }^{13}$.

The GBD 2019 estimated the exposure of the Brazilian population to each risk, based on dietary recall sources obtained from systematic reviews, national surveys conducted by the Brazilian Ministry of Health (MoH), and the Brazilian Institute of Geography and Statistics (IBGE), such as the Surveillance System for Risk and Protective Factors for Chronic Diseases by Telephone Survey (Vigitel) and the Consumer Expenditure Survey (POF), and available data from the Food and Agriculture Organization of the United Nations (FAO) Supply and Utilization Accounts. When local data is not available, GBD may also use sources from other countries ${ }^{13}$.

Since the data sources to estimate nutrient intake may have specific biases, a network meta-regression (MR-BRT) was applied in GBD 2019 to adjust the data obtained by different methods and make them comparable with those from the gold standard methods ${ }^{13}$. The gold standard data source for all dietary risks is the 24-hour dietary record, except for sodium whose gold standard is the 24-hour urinary sodium (Supplementary Material Table 1). The exposure estimates for each dietary risk, corresponded to the average intake in grams per person per day of each nutrient, by age, sex, year, and location were modeled using a spatiotemporal Gaussian process regression (ST-GPR) framework ${ }^{12,13}$.

\section{Optimal Level of Dietary Risk Factors Intake}

In GBD 2019, the theoretical minimum risk exposure level (TMREL) was set to zero for all harmful dietary risks on the rise, except for sodium which was defined in $3 \mathrm{~g} /$ day $(1-5 \mathrm{~g} / \text { day })^{13}$. For dietary factors in which exposure reduces an outcome (such as fruit intake), the 85th percentile of exposure found in the cohorts or trials were used in the meta-regression of each risk-outcome pair. Therefore, the TMREL was calculated using the average of these numbers and weighing them by the relative global magnitude of each outcome ${ }^{13}$. The TMREL applied for each dietary risk can also be found in the Supplementary Material Table 1.

\section{Burden of Disease Attributable to Dietary Risks}

Risk-outcome pairs were selected in the literature based on most recent systematic reviews and meta-analysis with the aim of identifying epidemiological evidence to support the causal relationship between the 15 dietary risks and their respective health outcomes (the risk-outcome pairs are shown in the Supplementary Material Table 2). After that, relative risks for each risk-outcome pair by age, sex, and location were obtained by meta-analysis derived from cohort studies or trials included in the GBD 2019 publications. The size of the effect of the associations and uncertainties for each cause were also estimated by meta-regression. The population attributable fraction (PAF) was calculated using the information from the counterfactual scenario of TMREL. The proportion of each dietary risk on its related outcome was then estimated by multiplying the PAF by the disease burden envelope $e^{12-14}$.

\section{Data Analysis}

The burden of disease in this study was measured using deaths and DALYs stratified by sex, age group, and states, in 1990 and 2019. The estimates were represented through absolute numbers, proportions, and age-standardized rates per 100,000 inhabitants. Age-standardized rates in the GBD were calculated using the standard GBD world population. The investigated population consisted of Brazilian adults, aged 25 years or older.

Considering the analytical strategy, we first presented the estimated mean daily intake of each dietary risk in 2019. The number of deaths and DALYs in 2019 were then stratified by each specific outcome. The deaths and DALYs rates from 1990 to 2019 , together with the percentage change over the period, were also presented. The proportion of deaths and DALYs due to noncommunicable diseases attributable to dietary risks in 2019 were analyzed by sex, age, and for each state.

The $95 \%$ uncertainty intervals (95\% UI) were estimated from 1,000 calculations of each parameter distribution in each iteration. The mean and its lower and upper limits were calculated based on the 2.5 and 97.5 percentiles $^{12}$.

\section{RESULTS}

In 2019, the intake of healthy foods and nutrients, such as fruits, milk, whole grains, vegetables, calcium, fiber, seafood omega-3 fatty acids, and PUFA were suboptimum (lower than TMREL) 
among Brazilian adults aged 25 years or older. Legumes, nuts, and seeds were the only healthy dietary factors with intakes higher than TMREL. The consumption of all the unhealthy dietary factors (processed and red meat, SSBs, TFA, and sodium) exceeded the minimal risk level.

We highlight the higher consumption of healthy nutrients, such as fiber, calcium, omega-3, and PUFA in the Southeastern, Southern, and Midwestern states. Milk consumption was high in the Midwestern states. The lowest average vegetable, nuts and seeds, PUFA, calcium, and omega-3 consumptions were observed in the Northeastern states. The Federal District stands out for the high average consumption of vegetables, fruit, legumes, nuts and seeds, whole grains, PUFA, calcium, and omega-3, as well as for the SSBs. In São Paulo, red meat was the most prominent (Figure 1; Supplementary Material Table 3).

Diet high in red meat, followed by a diet low in whole grains and high in sodium, were the main causes of NCDs deaths and DALYs for both sexes and all age groups in 1990 and in 2019. The leading cause of deaths and DALYs were CVDs, diabetes mellitus, and neoplasms (Figure 2; Supplementary Material Table 4).

The age-standardized mortality and DALYs rates for the total and the 15 individual leading dietary risks are ranked in Figure 3. There was a total of 134.7 (95\% UI: 108.2-169.9) and 65.3 (95\% UI: 51.9-83.9) deaths per 100,000 inhabitants due to NCDs attributable to dietary risks in 1990 and 2019, respectively, with a $-51.5 \%$ reduction between 1990 and 2019. The exception was for low milk intake, which remained stable during the period. The highest age-standardized mortality declines were observed for diets low in legumes $(-87.5 \%)$, nuts and seeds $(-87.5 \%)$, and fruits $(-65.5 \%)$. Low intake of whole grains was the leading risk factor in $1990(29.8$; 95\% UI: 14.7-38.2 deaths per 100,000 inhabitants), followed by a high intake of sodium and red meat. In 2019 , the highest rates were attributed to a high intake of red meat (17.1; 95\% UI: 12.1-21.8 deaths per 100,000 inhabitants), a low intake of whole grains, and a high intake of sodium (Figure 3A).

When compared to age-standardized mortality rates, trends in age-standardized DALYs rates were similar. The age-standardized DALYs rates of NCDs attributable to dietary risks was $3,113.7$ (95\% UI: 2,568.2-3,844.1) per 100,000 inhabitants in 1990 and $1,617.7$ (95\% UI: 1,314.7-2,004.5) per 100,000 inhabitants in 2019, corresponding to a $-48.8 \%$ reduction over the period. The highest reductions were observed for a diet low in legumes $(-88.8 \%)$, nuts and seeds (-88.1\%), and fruits (-65.5\%). On the other hand, positive trends were observed for a diet high in processed meat (5.4\%) and low in milk (2.3\%) (Figure 3B).

Although mortality and DALYs rates due to NCDs attributable to a diet high in TFA, SSBs, and processed meat have declined from 1990 to 2019, they did rise some positions in the ranking over time (Figure 3A; Figure 3B).

Figure 4 shows the proportion of deaths and DALYs due to NCDs attributable to individual dietary risks by sex and age in 2019 (Supplementary Material Table 5). Compared to women, the proportion of deaths caused by dietary risks were higher among men. The highest proportion of deaths for both male and female individuals were between 45 and 49 years of age. The highest proportion of deaths by dietary risks in both sexes and almost all age groups were due to a high intake of red meat, followed by a low intake of whole grains and a high intake of sodium (Figure 4A; Figure 4B). When evaluating the proportion of DALYs, we also found that it was higher among men when compared to women. Additionally, it was observed that males, aged between 50 and 54 years, and females, aged between 65 and 69 years, presented the highest proportion of DALYs attributable to dietary risks. As observed for the proportion of deaths, diets high in red meat, low in whole grains, and high in sodium were the leading dietary risks contributing to the proportion of DALYs in both sexes and in almost all age categories (Figure 4C; Figure 4D).

According to Figure 5, the proportion of the total burden of DALYs due to NCDs, for both sexes and all ages in Brazil was 8.36\%. Maranhão, Rio de Janeiro, and Alagoas presented the highest proportions of DALYs attributable to dietary risks in $2019(9.60 \%$, $9.58 \%$, and $9.57 \%$, respectively). The $95 \%$ UI of the proportion of DALYs and the proportion of deaths in Brazil and its states in 2019 can be found in the Supplementary Material Tables 6 and 7.

\section{DISCUSSION}

The present study evidenced that age-standardized mortality and DALYs rates due to NCDs attributable to diet in Brazil have decreased from 1990 to 2019. However, Brazilian diet still requires improvements. Among the dietary risks, a diet high in red meat and sodium but low in whole grains were the main contributors to the burden of NCDs. The proportion of diet-related deaths and DALYs was higher in males, in the middle-aged population, and in the states of Maranhão, Rio de Janeiro, and Alagoas.

Although healthy patterns of diets were observed in several regions, only legumes, nuts, and seeds achieved the optimum intake, according to GBD 2019. One previous study showed a traditional dietary pattern among Brazilian adults, with a high intake of rice and beans, and an increase in the consumption of whole grains, fruits, and vegetables with age; however, young adults reported a high-calorie intake and a poor-nutrient profile in their $\operatorname{diets}^{15}$. This means a coexistence of healthy and unhealthy habits in the Brazilian population. Comparing GBD 2019 estimates with the National Dietary Survey (NDS) 2017/2018, a nationwide survey in Brazil that monitors food consumption based on a POF subsample, we found that, although the high intake of beans supports the GBD estimates, the nuts and seeds consumption estimates are quite discrepant ${ }^{16}$. According to the NDS, nuts and seed consumption are not adequate among Brazilians ${ }^{16}$, and these differences need further investigation and adjustments. Additionally, the differences among states could be explained by cultural and sociodemographic determinants ${ }^{17}$.

Our findings also emphasize that approximately $10 \%$ of the NCDs could be reduced in Brazil by implementing a healthier diet. It is well-known that diet is a determining factor of human health and well-being, while unhealthy diets are one of the causes associated with the burden of $\mathrm{NCDs}^{18}$. However, over the years, changes in the eating patterns have contributed to the occurrence of diet-related NCDs, such as CVDs, diabetes mellitus, and neoplasms ${ }^{2,4}$. 


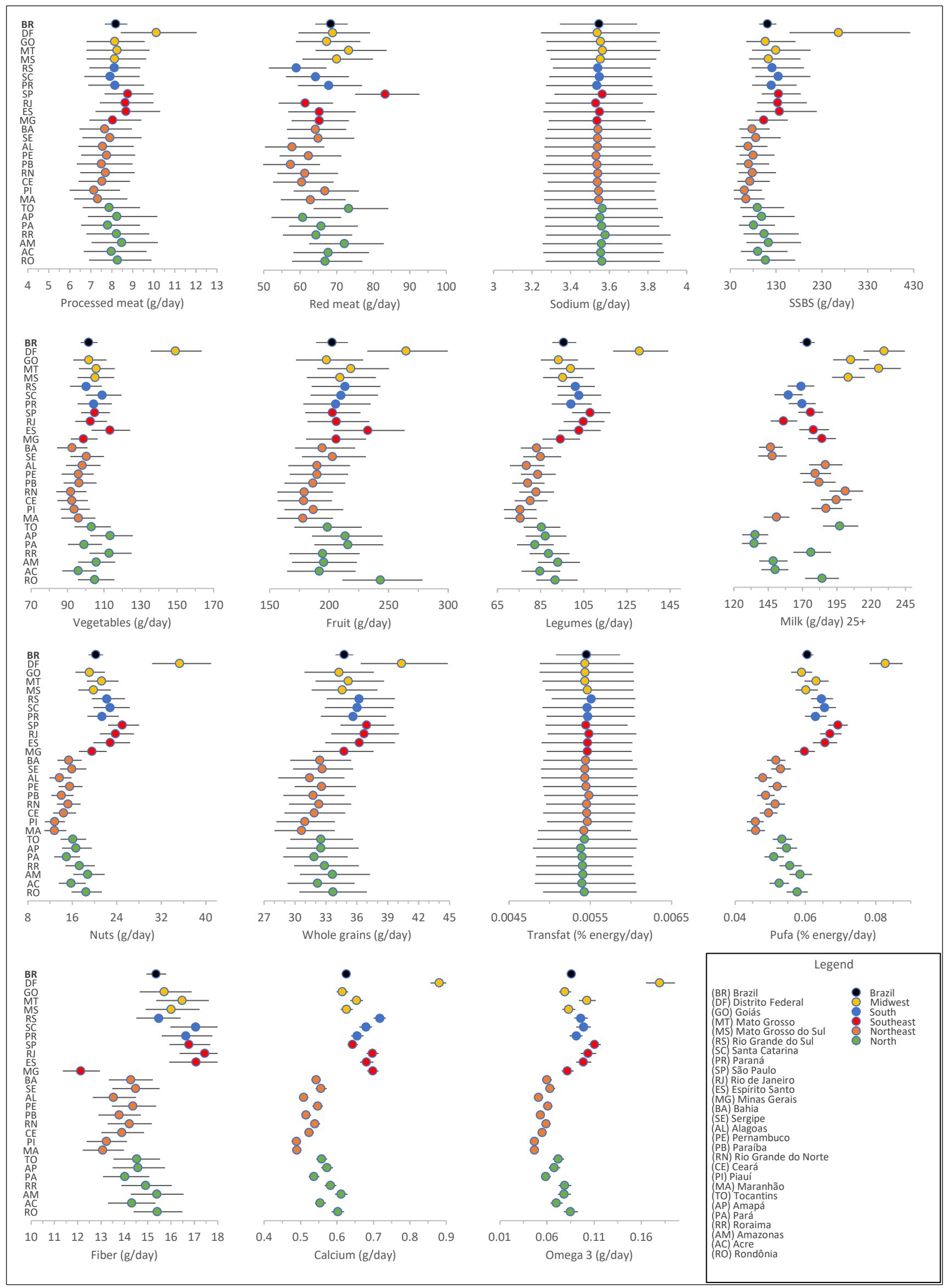

FIGURE 1: Mean intake of dietary factors among adults aged 25 years or older in Brazil and its states in 2019. 
A

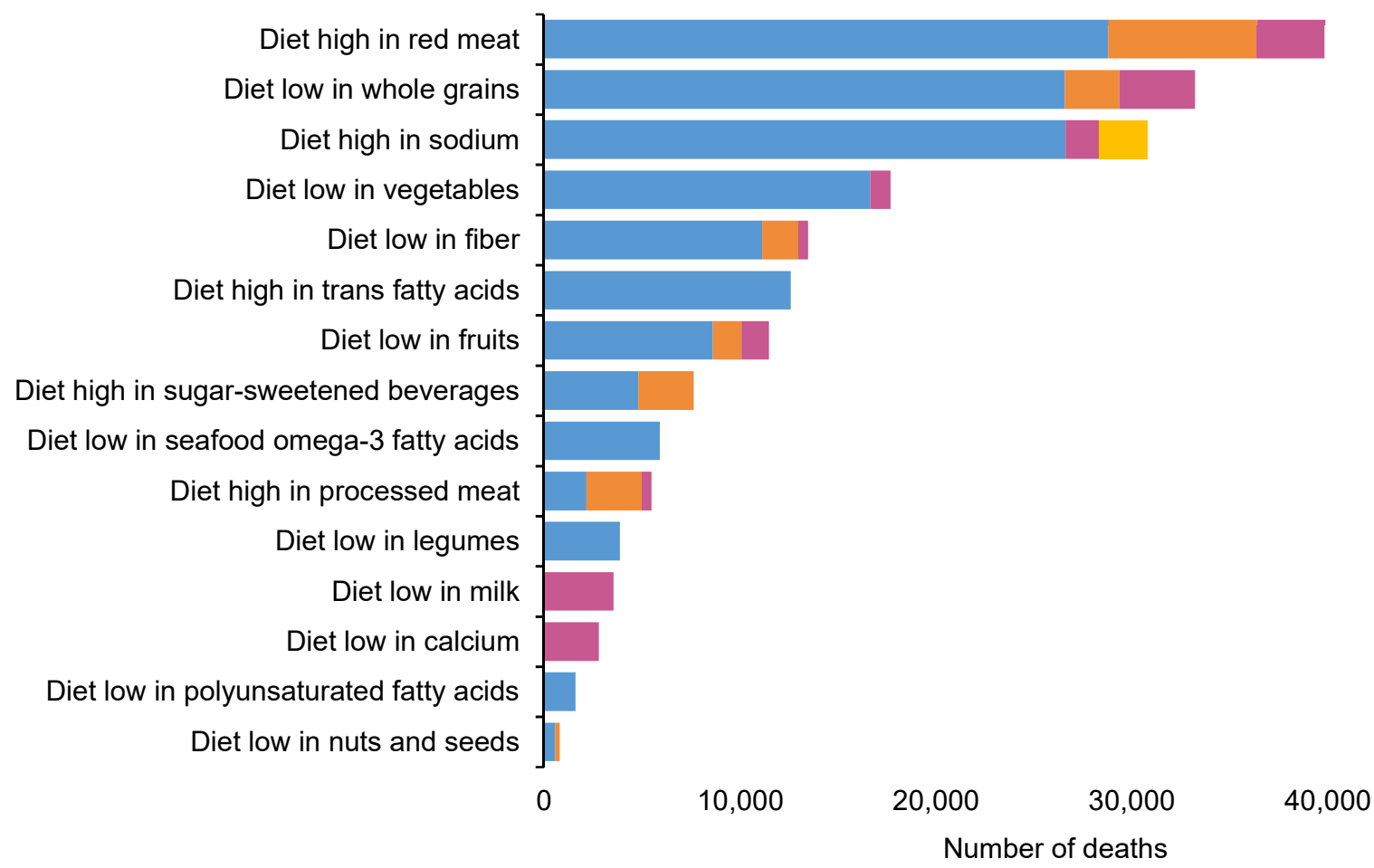

B

Diet high in red meat Diet low in whole grains

Diet high in sodium

Diet low in vegetables

Diet low in fiber

Diet low in fruits

Diet high in trans fatty acids

Diet high in sugar-sweetened beverages

Diet high in processed meat

Diet low in seafood omega-3 fatty acids

Diet low in milk Diet low in legumes

Diet low in calcium

Diet low in polyunsaturated fatty acids

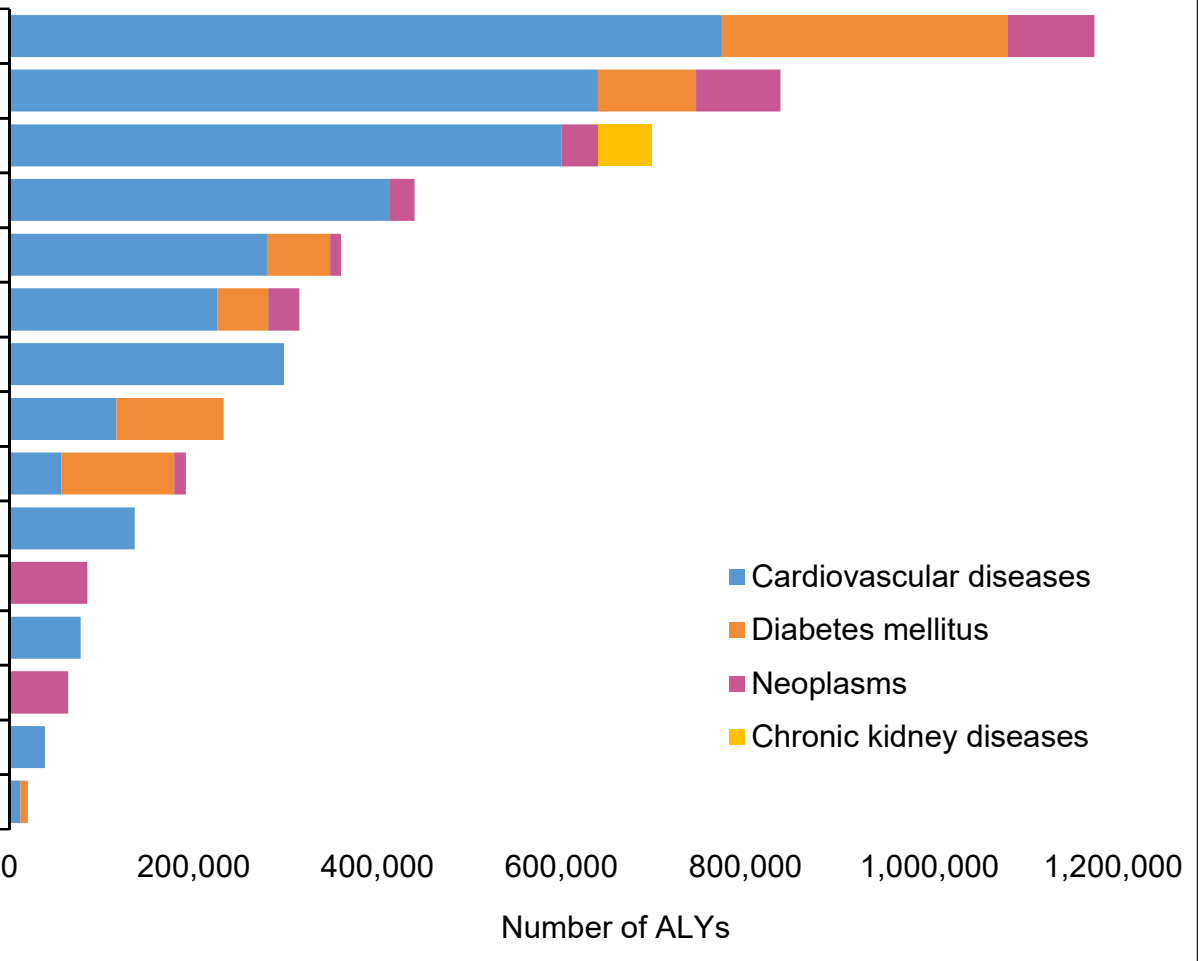

FIGURE 2: Number of deaths (A) and DALYS (B) due to non-communicable diseases attributable to dietary risks for both sexes and all ages in Brazil, 2019. Legend: DALYs: Disability-adjusted life years. 


\begin{tabular}{|c|c|c|c|c|c|c|}
\hline \multicolumn{7}{|l|}{ A } \\
\hline \multicolumn{2}{|r|}{1990} & \multirow{2}{*}{\begin{tabular}{|c|}
$\begin{array}{c}\text { Age-standardized } \\
\text { mortality rate } \\
\text { (95\%UI) }\end{array}$ \\
29.8 \\
$(14.7-38.2)$ \\
\end{tabular}} & \multicolumn{2}{|r|}{2019} & \multirow{2}{*}{\begin{tabular}{|c|}
$\begin{array}{c}\text { Age-standardized } \\
\text { mortality rate } \\
\text { (95\%UI) }\end{array}$ \\
17.1 \\
$(12.1-21.8)$ \\
\end{tabular}} & \multirow{2}{*}{\begin{tabular}{|c|}
$\begin{array}{c}\% \text { change } \\
1990-12019\end{array}$ \\
-19.3 \\
\end{tabular}} \\
\hline 1 & Diet low in whole grains & & 1 & Diet high in red meat & & \\
\hline 2 & Diet high in sodium & $\begin{array}{c}28.0 \\
(1.6-74.6)\end{array}$ & 2 & Diet low in whole grains & $\begin{array}{c}14.4 \\
(7.8-18.4)\end{array}$ & -51.7 \\
\hline 3 & Diet high in red meat & $\begin{array}{c}21.2 \\
(12.7-29.9)\end{array}$ & 3 & Diet high in sodium & $\begin{array}{c}13.4 \\
(0.9-36.6)\end{array}$ & -52.1 \\
\hline 4 & Diet low in vegetables & $\begin{array}{c}20.0 \\
(13.6-25.9)\end{array}$ & 4 & Diet low in vegetables & $\begin{array}{c}7.6 \\
(4.8-10.3)\end{array}$ & -62.0 \\
\hline 5 & Diet low in fiber & $\begin{array}{c}16.9 \\
(9.4-24.4)\end{array}$ & 5 & Diet low in fiber & $\begin{array}{c}5.9 \\
(3.3-8.7)\end{array}$ & -65.1 \\
\hline 6 & Diet low in fruits & $\begin{array}{c}14.5 \\
(9.2-19.8)\end{array}$ & 6 & Diet high in trans fatty acids & $\begin{array}{c}5.5 \\
(0.5-7.3)\end{array}$ & -58.0 \\
\hline 7 & Diet low in legumes & $\begin{array}{c}13.6 \\
(1.4-22.8)\end{array}$ & 7 & Diet low in fruits & $\begin{array}{c}5.0 \\
(3.2-7.0)\end{array}$ & -65.5 \\
\hline 8 & Diet high in trans fatty acids & $\begin{array}{c}13.1 \\
(1.2-17.3)\end{array}$ & 8 & Diet high in sugar-sweetened beverages & $\begin{array}{c}3.3 \\
(2.2-4.2)\end{array}$ & -35.3 \\
\hline 9 & Diet low in seafood omega-3 fatty acids & $\begin{array}{c}5.6 \\
(3.3-6.9)\end{array}$ & 9 & Diet low in seafood omega- 3 fatty acids & $\begin{array}{c}2.6 \\
(1.7-3.2)\end{array}$ & -53.6 \\
\hline 10 & Diet high in sugar-sweetened beverages & $\begin{array}{c}5.1 \\
(3.6-6.4)\end{array}$ & 10 & Diet high in processed meat & $\begin{array}{c}2.4 \\
(1.2-4.1)\end{array}$ & -7.7 \\
\hline 11 & Diet low in nuts and seeds & $\begin{array}{c}3.2 \\
(1.2-5.9)\end{array}$ & 11 & Diet low in legumes & $\begin{array}{c}1.7 \\
(0.2-3.3)\end{array}$ & -87.5 \\
\hline 12 & Diet high in processed meat & $\begin{array}{c}2.6 \\
(1.2-5.2)\end{array}$ & 12 & Diet low in milk & $\begin{array}{c}1.5 \\
(0.8-2.3)\end{array}$ & 0 \\
\hline 13 & Diet low in calcium & $\begin{array}{c}1.6 \\
(1.2-2.2)\end{array}$ & 13 & Diet low in calcium & $\begin{array}{c}1.2 \\
(0.7-1.9)\end{array}$ & -25.0 \\
\hline 14 & Diet low in milk & $\begin{array}{c}1.5 \\
(0.8-2.2)\end{array}$ & 14 & Diet low in polyunsaturated fatty acids & $\begin{array}{c}0.7 \\
(0.2-1.5)\end{array}$ & -46.2 \\
\hline 15 & Diet low in polyunsaturated fatty acids & $\begin{array}{c}1.3 \\
(0.4-2.8)\end{array}$ & 15 & Diet low in nuts and seeds & $\begin{array}{c}0.4 \\
(0.2-0.7)\end{array}$ & -87.5 \\
\hline \multicolumn{2}{|c|}{ Dietary risks } & $\begin{array}{c}134.7 \\
(108.2-169.9)\end{array}$ & \multicolumn{2}{|c|}{ Dietary risks } & $\begin{array}{c}65.3 \\
(51.9-83.9)\end{array}$ & -51.5 \\
\hline \multicolumn{7}{|l|}{ B } \\
\hline \multicolumn{2}{|r|}{1990} & $\begin{array}{c}\text { Age-standardized } \\
\text { DALYs rate } \\
\text { (95\%UI) }\end{array}$ & \multicolumn{2}{|r|}{2019} & \begin{tabular}{|c|} 
Age-standardized \\
DALYs rate \\
$(95 \% \mathrm{UI})$
\end{tabular} & $\begin{array}{c}\text { \% change } \\
1990-12019\end{array}$ \\
\hline 1 & Diet low in whole grains & $\begin{array}{c}676.9 \\
(335.5-858.7)\end{array}$ & 1 & Diet high in red meat & $\begin{array}{c}487.0 \\
(358.1-606.1)\end{array}$ & -14.5 \\
\hline 2 & Diet high in sodium & $\begin{array}{c}603.9 \\
(34.4-1.618 .1)\end{array}$ & 2 & Diet low in whole grains & $\begin{array}{c}348.7 \\
(193.7-444.3)\end{array}$ & -48.5 \\
\hline 3 & Diet high in red meat & $\begin{array}{c}569.5 \\
(361.5-774.9)\end{array}$ & 3 & Diet high in sodium & $\begin{array}{c}293.1 \\
(18.3-805.6)\end{array}$ & -51.5 \\
\hline 4 & Diet low in vegetables & $\begin{array}{c}476.8 \\
(311.0-628.2)\end{array}$ & 4 & Diet low in vegetables & $\begin{array}{c}182.5 \\
(112.5-248.4)\end{array}$ & -61.7 \\
\hline 5 & Diet low in fiber & $\begin{array}{c}405.6 \\
(233.9-573.2)\end{array}$ & 5 & Diet low in fiber & $\begin{array}{c}150.4 \\
(86.4-214.9)\end{array}$ & -62.9 \\
\hline 6 & Diet low in fruits & $\begin{array}{c}378.7 \\
(251.8-518.0\end{array}$ & 6 & Diet low in fruits & $\begin{array}{c}130.8 \\
(84.2-183.4)\end{array}$ & -65.5 \\
\hline 7 & Diet low in legumes & $\begin{array}{c}296.0 \\
(31.2-491.2)\end{array}$ & 7 & Diet high in trans fatty acids & $\begin{array}{c}124.1 \\
(11.4-165.2)\end{array}$ & -56.4 \\
\hline 8 & Diet high in trans fatty acids & $\begin{array}{c}284.9 \\
(24.4-375.3)\end{array}$ & 8 & Diet high in sugar-sweetened beverages & $\begin{array}{c}97.1 \\
(65.5-125.8)\end{array}$ & -21.1 \\
\hline 9 & Diet high in sugar-sweetened beverages & $\begin{array}{c}123.0 \\
(84.4-157.0)\end{array}$ & 9 & Diet high in processed meat & $\begin{array}{c}79.4 \\
(42.8-126.2)\end{array}$ & 5.4 \\
\hline 10 & Diet low in seafood omega-3 fatty acids & $\begin{array}{c}121.6 \\
(70.1-149.5)\end{array}$ & 10 & Diet low in seafood omega-3 fatty acids & $\begin{array}{c}56.9 \\
(36.4-69.9)\end{array}$ & -53.2 \\
\hline 11 & Diet high in processed meat & $\begin{array}{c}75.3 \\
(34.9-139.7)\end{array}$ & 11 & Diet low in milk & $\begin{array}{c}35.2 \\
(17.7-52.2)\end{array}$ & 2.3 \\
\hline 12 & Diet low in nuts and seeds & $\begin{array}{c}72.2 \\
(28.9-133.4)\end{array}$ & 12 & Diet low in legumes & $\begin{array}{c}33.0 \\
(4.8-63.7)\end{array}$ & -88.8 \\
\hline 13 & Diet low in calcium & $\begin{array}{c}35.3 \\
(25.4-47.6)\end{array}$ & 13 & Diet low in calcium & $\begin{array}{c}26.7 \\
(15.6-41.4)\end{array}$ & -24.4 \\
\hline 14 & Diet low in milk & $\begin{array}{c}34.4 \\
(19.1-49.5)\end{array}$ & 14 & Diet low in polyunsaturated fatty acids & $\begin{array}{c}16.1 \\
(4.2-35.9)\end{array}$ & -40.4 \\
\hline 15 & Diet low in polyunsaturated fatty acids & $\begin{array}{c}27.0 \\
(8.3-58.9)\end{array}$ & 15 & Diet low in nuts and seeds & $\begin{array}{c}8.6 \\
(5.5-15.3)\end{array}$ & -88.1 \\
\hline Dietar & risks & $\begin{array}{c}3,113.7 \\
(2,568.2-3,844.1) \\
\end{array}$ & Dietary & risks & $\begin{array}{c}1,617.7 \\
(1,314.7-2,004.5)\end{array}$ & -48.0 \\
\hline 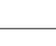 & Ascending order in rank & & & & & \\
\hline ....... & Descending order in rank & & & & & \\
\hline 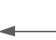 & $\longrightarrow$ Same order in rank & & & & & \\
\hline
\end{tabular}

FIGURE 3: Ranking of the age-standardized mortality rate per 100,000 inhabitants (A) and DALYs rate per 100,000 inhabitants (B) due to non-communicable diseases attributable to total and individual dietary risks for both sexes in Brazil and the percentage change from 1990 to 2019. Legend: $\mathbf{9 5 \%}$ UI: 95\% Uncertainty interval. DALYs: Disability-adjusted life years. 


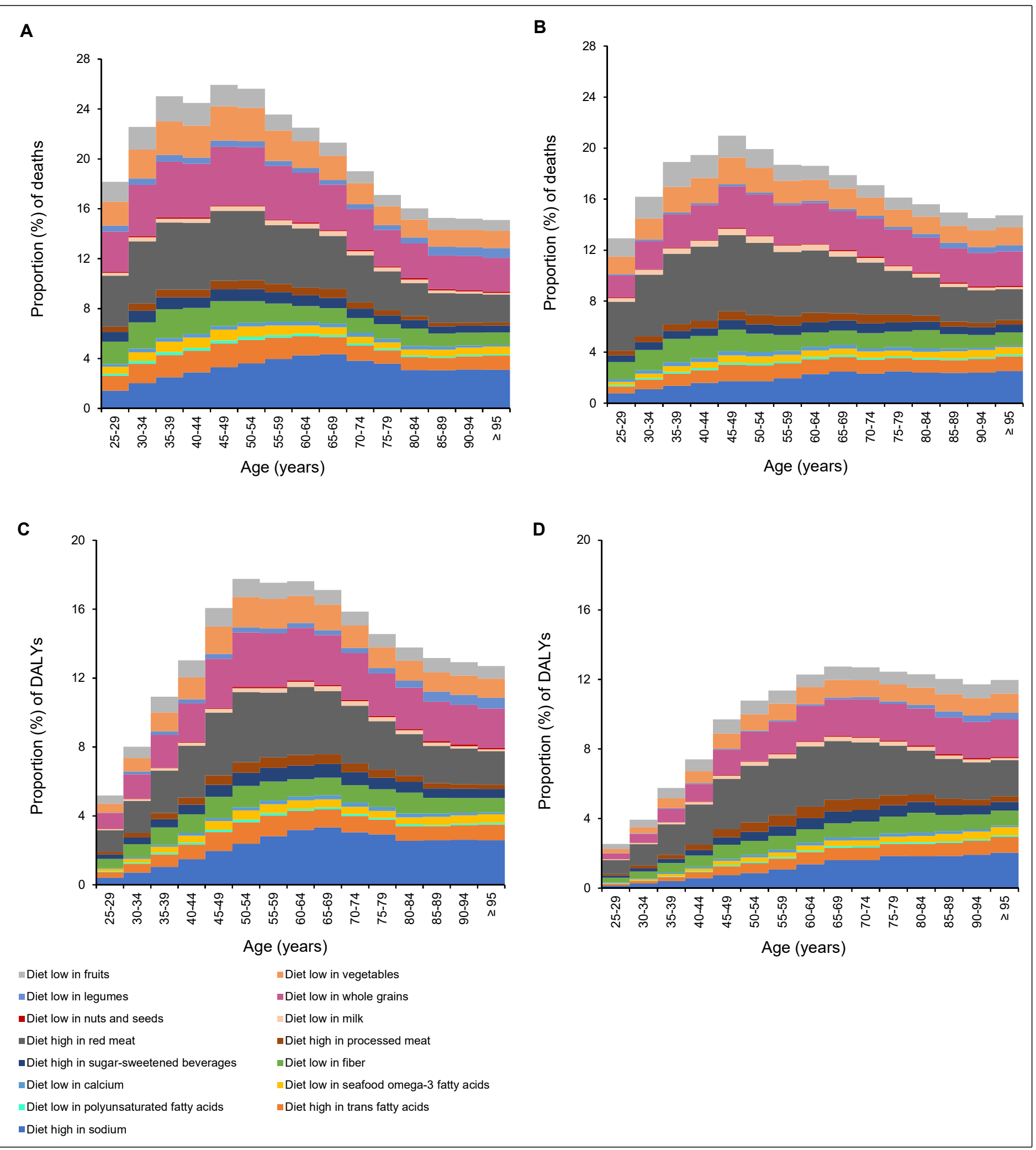

FIGURE 4: Proportion of deaths among male (A) and female (B) individuals and proportion of DALYs among male (C) and female (D) individuals due to non-communicable diseases attributable to dietary risks by sex and age in Brazil, 2019. Legend: DALYs: Disability-adjusted life years. 


\begin{tabular}{|c|c|c|c|c|c|c|c|c|c|c|c|c|c|c|c|c|}
\hline 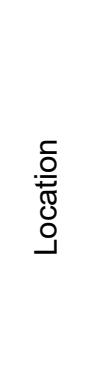 & 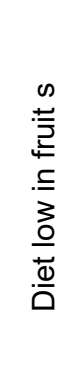 & 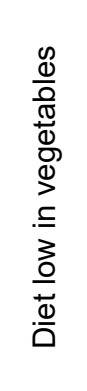 & 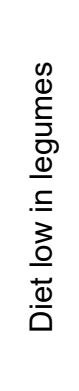 & 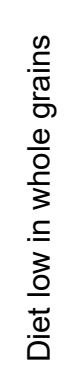 & 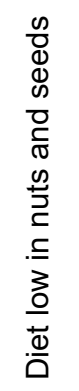 & 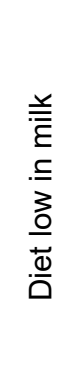 & 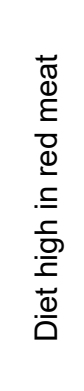 & 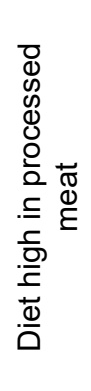 & 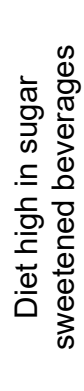 & 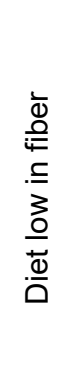 & 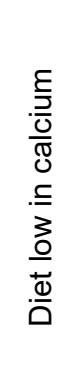 & 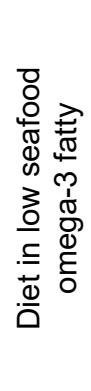 & 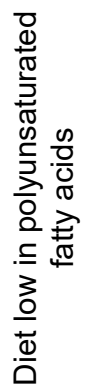 & 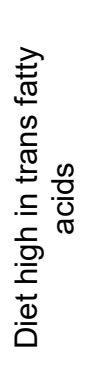 & 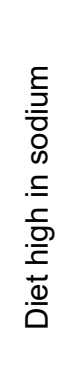 & 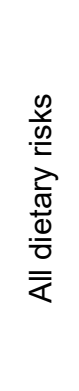 \\
\hline Brazil & 0.68 & 95 & 17 & 1.80 & 0.04 & 0.18 & 2.54 & 0.41 & 0.50 & .78 & 0.14 & 0.29 & 0.08 & 0.64 & 1.51 & 8.36 \\
\hline$A C$ & 0.56 & 0.67 & 0.17 & 1.25 & 0.04 & 0.11 & 1.87 & 0.30 & 0.36 & 0.63 & 0.10 & 0.20 & 0.07 & 0.42 & 1.14 & 6.15 \\
\hline $\mathrm{AL}$ & 0.90 & 1.05 & 0.35 & 2.01 & 0.09 & 0.11 & 2.75 & 0.48 & 0.58 & 1.12 & 0.12 & 0.34 & 0.14 & 0.68 & 1.63 & 9.57 \\
\hline AP & 0.50 & 0.63 & 0.14 & 1.23 & 0.03 & 0.10 & 1.78 & 0.31 & 0.36 & 0.59 & 0.08 & 0.20 & 0.06 & 0.42 & 1.12 & 5.96 \\
\hline AM & 0.51 & 0.59 & 0.10 & 1.18 & 0.03 & 0.13 & 1.96 & 0.34 & 0.38 & 0.50 & 0.09 & 0.18 & 0.05 & 0.38 & 1.10 & 6.00 \\
\hline BA & 0.70 & 0.98 & 0.24 & 1.74 & 0.06 & 0.16 & 2.55 & 0.41 & 0.49 & 0.86 & 0.14 & 0.29 & 0.10 & 0.58 & 1.51 & 8.43 \\
\hline CE & 0.77 & 0.95 & 0.29 & 1.71 & 0.06 & 0.11 & 2.17 & 0.35 & 0.44 & 0.88 & 0.14 & 0.30 & 0.12 & 0.60 & 1.39 & 7.97 \\
\hline DF & 0.25 & 0.44 & 0.02 & 1.23 & 0.02 & 0.13 & 2.12 & 0.41 & 0.58 & 0.22 & 0.07 & 0.16 & 0.02 & 0.43 & 1.11 & 5.96 \\
\hline ES & 0.53 & 0.94 & 0.11 & 1.77 & 0.03 & 0.17 & 2.48 & 0.43 & 0.53 & 0.53 & 0.12 & 0.28 & 0.06 & 0.65 & 60 & .18 \\
\hline GO & 0.70 & 0.93 & 0.16 & 1.80 & 0.04 & 0.15 & 2.44 & 0.39 & 0.47 & 0.65 & 0.13 & 0.30 & 0.09 & 0.66 & 1.45 & 8.09 \\
\hline MA & 0.95 & 1.12 & 0.44 & 2.08 & 0.10 & 0.11 & 2.68 & 0.42 & 0.56 & 1.20 & 0.12 & 0.38 & 0.17 & 0.74 & 1.60 & 9.60 \\
\hline MT & 0.53 & 0.81 & 0.11 & 1.59 & 0.03 & 0.11 & 2.47 & 0.41 & 0.52 & 0.54 & 0.10 & .24 & .06 & 0.57 & 1.34 & 7.51 \\
\hline MS & 0.64 & 0.95 & 0.16 & 1.86 & 0.04 & 0.14 & 2.60 & 0.41 & 0.53 & 0.65 & 0.13 & 0.31 & 0.08 & 0.69 & 1.53 & 8.42 \\
\hline MG & 0.62 & 0.91 & 0.13 & 1.60 & 0.03 & 0.17 & 2.33 & 36 & 0.42 & 1.28 & 0.11 & .26 & .07 & 56 & 1.40 & 7.82 \\
\hline PA & 0.53 & 0.83 & 0.23 & 1.58 & 0.05 & 0.13 & 2.32 & 0.37 & 0.45 & 0.80 & 0.11 & 0.26 & 10 & 53 & .32 & 7.47 \\
\hline PB & 0.87 & 1.04 & 0.36 & 2.01 & 0.08 & 0.12 & 2.44 & 0.45 & 0.57 & 1.04 & 0.13 & 0.36 & 0.14 & 0.71 & 1.54 & 9.13 \\
\hline PR & 0.67 & 0.92 & 0.12 & 1.79 & 0.03 & 0.21 & 2.51 & 0.42 & 0.53 & 0.57 & 0.15 & 0.28 & 0.07 & 0.62 & 1.52 & 8.26 \\
\hline PE & 0.83 & 1.11 & 0.31 & 2.11 & 0.07 & 0.13 & 2.69 & 0.45 & 0.56 & 0.97 & 0.12 & 0.38 & 0.14 & 0.78 & 1.59 & 9.41 \\
\hline PI & 0.84 & 0.98 & 0.38 & 1.83 & 09 & 0.10 & 2.65 & 0.39 & 0.51 & 1.06 & 0.13 & 0.32 & 0.14 & .62 & 1.49 & 8.84 \\
\hline RJ & 0.76 & 1.12 & 0.11 & 2.16 & 0.04 & 0.26 & 2.83 & 0.52 & 0.62 & 0.58 & 0.15 & 0.35 & 0.08 & 0.81 & 1.73 & 9.58 \\
\hline RN & 0.77 & 0.91 & 0.29 & 1.88 & 07 & 0.13 & 2.24 & 45 & 0.54 & 0.86 & 0.14 & .32 & .12 & 66 & 1.37 & 8.29 \\
\hline RS & 0.67 & 0.97 & 0.11 & 1.79 & 0.03 & 0.26 & 2.26 & 0.40 & 0.49 & 0.74 & 0.15 & 0.28 & 0.06 & 0.62 & 1.48 & 8.13 \\
\hline RO & 0.49 & 0.87 & 0.17 & 1.69 & 0.04 & 0.12 & 2.32 & 0.41 & 0.50 & 0.67 & 0.10 & 0.27 & 8 & 0.61 & 1.42 & 7.70 \\
\hline $\mathrm{RR}$ & 0.50 & 0.60 & 0.14 & 1.32 & 0.04 & 0.10 & 1.94 & 0.39 & 0.46 & 0.58 & 0.09 & 0.20 & 0.06 & 0.43 & 1.16 & 6.33 \\
\hline SC & 0.58 & 0.79 & 0.10 & 1.64 & 0.03 & 0.20 & 2.21 & 0.37 & 0.48 & 0.47 & 0.13 & 0.26 & 0.06 & 0.59 & 1.39 & 7.42 \\
\hline SP & 0.62 & 0.93 & 0.07 & 1.81 & 0.03 & 0.23 & 2.80 & 0.41 & 0.48 & 0.61 & 0.16 & 0.29 & 0.06 & 0.67 & 1.57 & 8.38 \\
\hline SE & 0.66 & 0.82 & 0.21 & 1.71 & 0.06 & 0.15 & 2.50 & 0.45 & 0.52 & 0.82 & 0.12 & 0.28 & 0.10 & 0.57 & 1.36 & 8.10 \\
\hline TO & 0.68 & 0.93 & 0.24 & 1.77 & 0.05 & 0.11 & 2.70 & 0.40 & 0.49 & 0.83 & 0.11 & 0.29 & 0.10 & 0.63 & 1.49 & 8.43 \\
\hline
\end{tabular}

FIGURE 5: Proportion of disability-adjusted life years (DALYs) due non-communicable diseases attributable to dietary risks for both sexes and all ages in Brazil its states, 2019. Legend: AC: Acre; AL: Alagoas; AP: Amapá; AM: Amazonas; BA: Bahia; CE: Ceará; DF: Distrito Federal; ES: Espírito Santo; GO: Goiás; MA: Maranhão; MT: Mato Grosso; MS: Mato Grosso do Sul; MG: Minas Gerais; PA: Pará; PB: Paraíba; PR: Paraná; PE: Pernambuco; PI: Piauí; RJ: Rio de Janeiro; RN: Rio Grande do Norte; RS: Rio Grande do Sul; RO: Rondônia; RR: Roraima; SC: Santa Catarina; SP: São Paulo; SE: Sergipe; TO: Tocantins. Note: The dark red indicates the highest proportions of total DALYs in each location. The dark blue indicates the lowest proportion of total DALYs in each location.

The most important changes in the individuals' eating patterns have become more evident since the second half of the 20th century, with an increase in ultra-processed foods (UPF) over the traditional eating pattern ${ }^{19,20}$. UPF are nutritionally unbalanced and tend to be consumed in large quantities; therefore, their production until consumption are harmful to the heath, society, environment, and culture $^{21}$. Our study showed that diets high in UPF (such as SSBs and processed meat) and nutrients often found in these products (such as TFA) rose in the ranking between 1990 and 2019. Indeed, the caloric share of UPF available in Brazilian households increased between 2002-2003 (12.6\%) and 2017-2018 (18.4\%)

The Eat-Lancet Commission on healthy diets considers that a healthy and environmentally sustainable diet is based on whole 
grains, fruits, vegetables, legumes, nuts, and unsaturated oils, including a low to moderate amount of seafood and poultry, but it has little or no amount of red meat, processed meat, added sugar, refined grains, and starchy vegetables ${ }^{22}$. Contrary to these recommendations, our study found diets that are high in red meat, low in whole grains, and high in sodium were the major contributors to the burden of deaths and DALYs due to NCDs, highlighting the need for dietary changes in the Brazilian population.

In Brazil, the POF showed a reduction in the consumption of beef (21\%) and an increase in the consumption of pork (20\%) among adults ( $18-59$ years) and the elderly ( $\geq 60$ years) between the 2007 2008 and 2017-2018 surveys ${ }^{16}$. Nevertheless, the consumption of beef represented the second largest contributor to the total calories among in natura and minimally processed foods ${ }^{16}$. Concerns regarding high meat consumption involve health hazards, as there is strong evidence associating meat consumption with an increased risk of colorectal cancer ${ }^{23,24}$. Moreover, red meat production has a higher environmental impact by emitting more greenhouse gases and other pollutants, requiring a large amount of water and causing soil erosion ${ }^{25}$.

A high intake of sodium is a risk factor for high blood pressure and $\mathrm{CVDs}^{26}$. In Brazil, 54.4\% of excessive sodium intake was found in the most recent nationwide dietary survey ${ }^{16}$. Moreover, results from the NHS based on urinary sodium excretion has shown that nearly $30 \%$ of Brazilians have an intake of above $10 \mathrm{~g} /$ day, while only $3.4 \%$ have a consumption of salt according to the recommended levels ${ }^{27}$. Most of the sodium consumption comes from table salt and salt-based condiments (74.4\%); however, between 2002-2003 and 2008-2009 consumption of these ingredients decreased (76.2\% to $74.4 \%$ ), while contribution of processed foods with added salt increased (15.8\% to 18.9\%) in Brazil ${ }^{28}$. Between 2017-2018 about $20 \%$ of the calories in the Brazilian diet came from UPF, which often have a high sodium content ${ }^{29}$, which may in turn explain the burden attributable to this dietary risk found in this study ${ }^{16}$. Approaches aiming to reduce sodium consumption should consider the reduction of salt in preparations and in UPF, as well as in UPF intake ${ }^{30,31}$.

A low intake of whole grains is associated with an increased risk of all-cause mortality and NCDs, such as CVD, cancer, and diabetes mellitus ${ }^{32-34}$, corroborating our results. In agreement with our finding, the POF 2017-2018 showed that corn, oats, wheat, and other cereals provided only $1.1 \%$ of the total calories in the diets ${ }^{16}$. The reasons that may contribute to the lowest consumption of whole grains are their higher cost, greater difficulty to cook and chew, and less attractive colors for some consumers ${ }^{34}$.

Concerning gender, it seems that men are more involved in risk behaviors when compared to women, including inadequate eating patterns $^{35,36}$. The Vigitel, a Brazilian telephone survey carried out in the 26 state capitals and the Federal District with individuals aged $\geq 18$ years, revealed that $29.8 \%$ of the sample consumed five or more unprocessed or minimally processed foods in the day before the interview, with a higher frequency in woman $(32.3 \%)$ than in men $(26.9 \%)^{37}$. The same survey also showed that $18.2 \%$ of Brazilians consumed five or more UPF, which was higher in men $(21.8 \%)$ than in women $(15.1 \%)^{37}$. Compared with men, women have a better quality diet ${ }^{38}$. These differences might be explained by the greater implication of women in food preparation than men and by the concern of women regarding their health, even with the changes resulting from the insertion of women in the labor market ${ }^{39}$.

Our results also showed an increase in deaths and DALYs due to NCDs attributed to dietary risks with increasing age. Exposure to behavioral risk factors, including inadequate nutrition, can start early, consolidate in adulthood, and have negative effects during all life cycles. With population aging and increased life expectancy, reducing the burden of NCDs should be a priority to reduce the demands on the health system, guarantee economic development, and quality of life for individuals $\mathrm{s}^{40-42}$.

The present study found a reduction in the burden of NCDs attributable to dietary risks from 1990 to 2019 , reflecting the reduction in the total burden of NCDs in the country ${ }^{4}$. Brazil, along with other countries, has made some commitments over the past few years to face NCDs. The Global Action Plan sets a goal of reducing $25 \%$ of premature deaths from NCDs by $2025^{43}$. Continuing this commitment, the country has also assumed, together with the United Nations (UN), a 30\% reduction in premature deaths from NCDs by $2030^{44}$. Furthermore, we hypothesize that the burden reduction is partly explained by the strategic actions to tackle NCDs, including, for instance, greater access and use of services provided by the Unified Health System (SUS), such as coverage of public programs (for example, the Family Health Strategy), medical consultations, free drug distribution, organization of the emergency care network, diagnosis, and treatment ${ }^{45,46}$.

By contrast, our study's results elucidate that the Brazilian population's diet remains inadequate. It should be noted that health promotion goes beyond individual behaviors and does not depend only on the health sector. Much to the contrary, it also depends on intersectoral initiatives that guarantee favorable social and economic conditions for the adoption of a healthy lifestyle. In this direction, regulatory actions are essential, such as controlling advertising aimed at children, taxing UPF, expanding access to healthy foods, inducing policies on food production, distribution and access, educational campaigns, food labeling measures, healthy food supply in schools and workplaces, among others ${ }^{47,48}$.

Our study has some limitations. Data on food consumption and NCDs come from multiple sources, and each type of data has specific biases. The lack of data, low response rate, low quality information, and non-inclusion of certain population groups (such as the chronically ill, homeless, and illegal immigrants) can cause errors in the estimates. In addition, the strengths of evidence may vary between food and nutrients, and as a result, there may be an increase in the statistical uncertainty of exposure to dietary risks estimates. Moreover, when estimating the burden of NCDs attributable to dietary risks, the distribution of food factors within each unit of analysis (for example, age and sex) is assumed to be independent, which may result in an underestimation or overestimation of the combined effect of dietary factors ${ }^{12}$.

This study also has key strengths. A consistent and comparable methodology was used to determine the burden of NCDs attributable 
to dietary risk factors and thus beyond the risk factor prevalence estimation as is generally available. This advance also allows us to estimate the number of deaths and DALYs that could be prevented if these risks were reduced. Our findings reinforce the importance of ongoing actions to reduce premature deaths from NCDs. The use of data from the GBD, a public domain database, will also enable the monitoring of these actions over time. Moreover, these analyses may help to create more targeted financing policies and decisions in the field of food and nutrition with the purpose of promoting better health conditions for the Brazilian population.

\section{ACKNOWLEDGMENTS}

The authors would like to acknowledge the Institute for Health Metrics and Evaluation (IHME) for providing data to the study.

\section{FINANCIAL SUPPORT}

Conselho Nacional de Desenvolvimento e Científico e Tecnológico (CNPq/Brasil), grant number 442636/2019-9. Magda do Carmo Parajára is a research fellow from the Fundação de Amparo à Pesquisa do Estado de Minas Gerais (FAPEMIG/Brasil). Larissa Fernanda Fonseca Guedes is research fellow from the Coordenação de Aperfeiçoamento de Pessoal de Nível Superior (CAPES/Brasil). This study used data from the Institute for Health Metrics and Evaluation (IHME), funded by Bill \& Melinda Gates Foundation.

\section{AUTHORS' CONTRIBUTION}

ÍEM*: conception and design of the study, data analysis and interpretation, drafting and critical revision of the manuscript; MCP*: conception and design of the study, data analysis and interpretation, drafting and critical revision of the manuscript; LFFG: drafting and critical revision of the manuscript; ALM: critical revision of the manuscript; MCM: critical revision of the manuscript; MSFM: critical revision of the manuscript; EVJ: critical revision of the manuscript; DCM: critical revision of the manuscript. All authors were responsible for final approval of the version to be published. *These authors contributed equally to this work.

\section{CONFLICT OF INTEREST}

The authors declare that there are no conflicts of interest.

\section{ORCID}

Ísis Eloah Machado: 0000-0002-4678-2074

Magda do Carmo Parajára: 0000-0001-7019-1365

Larissa Fernanda Fonseca Guedes: 0000-0002-5330-7458

Adriana Lúcia Meireles: 0000-0002-1447-953X

Mariana Carvalho de Menezes: 0000-0002-3069-7959

Mariana Santos Felisbino-Mendes: 0000-0001-5321-5708

Eliseu Verly-Junior: 0000-0002-1101-8746

Deborah Carvalho Malta: 0000-0002-8214-5734

\section{REFERENCES}

1. World Health Organization (WHO). Global status report on noncommunicable diseases 2010. Geneva: WHO; 2011. 176 p.

2. World Health Organization (WHO). Noncommunicable diseases progress monitor 2020. Geneva: WHO; 2020. 236 p.

3. Institute for Health Metrics and Evaluation (IHME). GBD Results Tool [Internet]. Seattle: IHME; 2020 [cited 2021 Feb 21]. Available from: http://ghdx.healthdata.org/gbd-results-tool.

4. Malta DC, Duncan BB, Schmidt MI, Teixeira R, Ribeiro ALP, FelisbinoMendes MS, et al. Trends in mortality due to non-communicable diseases in the Brazilian adult population: national and subnational estimates and projections for 2030. Popul Health Metr. 2020;18(1):1-14.

5. Malta DC, França E, Abreu DMX, Perillo RD, Salmen MC, Teixeira RA, et al. Mortality due to noncommunicable diseases in Brazil, 1990 to 2015, according to estimates from the Global Burden of Disease study. Sao Paulo Med J. 2017;135(3):213-21.

6. World Health Organization (WHO). Noncommunicable diseases country profiles 2018. Geneva: WHO; 2018. 224 p.

7. Silva J, Kluczkovski A, Schmidt X, Frankowska A, Cruz G, Martins C, et al. Trends in the environmental impacts of unprocessed or minimally processed, processed, and ultra-processed animal products in Brazil over 30 years [Internet]. Paper presented at the LEAP 2020, 8 Dec 2020, Online [cited 2021 Apr 27]. Available from: https://openaccess.city.ac.uk/id/eprint/25384/.

8. Popkin BM, Corvalan C, Grummer-Strawn LM. Dynamics of the double burden of malnutrition and the changing nutrition reality. Lancet. 2020;395(10217):65-74

9. Ministério da Saúde (MS). Secretaria de Vigilância em Saúde. Departamento de Análise de Situação de Saúde. Plano de ações estratégicas para o enfrentamento das doenças crônicas não transmissíveis (DCNT) no Brasil 2011-2022. Brasília: MS; 2011. 160 p.

10. Melo SPSC, Cesse EAP, Lira PIC, Rissin A, Cruz RSBLC, Batista Filho M. Doenças crônicas não transmissíveis e fatores associados em adultos numa área urbana de pobreza do nordeste brasileiro. Cien Saude Colet. 2019;24(8):3159-68.

11. Diez Roux A, Barrientos-Gutierrez T, Caiaffa WT, Miranda JJ, Rodriguez $\mathrm{D}$, Sarmiento OL, et al. Urban health and health equity in Latin American cities: what COVID-19 is teaching us. Cities Health. 2020;1-5.

12. GBD 2017 Diet Collaborators. Health effects of dietary risks in 195 countries, 1990-2017: a systematic analysis for the Global Burden of Disease Study 2017. Lancet. 2019;393(10184):1958-72.

13. GBD 2019 Risk Factors Collaborators. Global burden of 87 risk factors in 204 countries and territories, 1990-2019: a systematic analysis for the Global Burden of Disease Study 2019. Lancet. 2020;396(10258):1223-49.

14. Ezzati M, Lopez AD, Rodgers A, Hoom SV, Murray CJL. Comparative Risk Assessment Collaborating Group. Selected major risk factors and global and regional burden of disease. Lancet. 2002;360(9343):1347-60.

15. Bezerra IN, Goldman J, Rhodes DG, Hoy MK, Souza AM, Chester DN, et al. Difference in adult food group intake by sex and age groups comparing Brazil and United States nationwide surveys. Nutr J. 2014;13(1):1-10.

16. Instituto Brasileiro de Geografia e Estatística (IBGE). Coordenação de Trabalho e Rendimento. Pesquisa de Orçamentos Familiares 2017-2018: análise do consumo alimentar pessoal no Brasil. Rio de Janeiro: IBGE; 2020. $120 \mathrm{p}$.

17. Santos JEM, Crispim SP, Murphy J, Cancela MC. Health, lifestyle and sociodemographic characteristics are associated with Brazilian dietary patterns: Brazilian National Health Survey. PloS One. 2021;16(2):e0247078. 
18. Kumanyika S, Afshin A, Arimond M, Lawrence M, McNaughton SA, Nishida C. Approaches to defining healthy diets: a background paper for the international expert consultation on sustainable healthy diets. Food Nutr Bull. 2020;41(Supl 2):7S-30S.

19. Popkin BM. The nutrition transition in the developing world. Dev Policy Rev. 2003;21(5-6):581-97.

20. Ribeiro H, Jaime PC, Ventura D. Alimentação e sustentabilidade. Estud Av. 2017;31(89):185-98.

21. Monteiro CA, Cannon G, Levy R, Moubarac JC, Jaime P, Martins AP, et al. NOVA. The star shines bright. World Nutr. 2016;7(1-3):28-38.

22. Willett W, Rockström J, Loken B, Springmann M, Lang T, Vermeulen S, et al. Food in the anthropocene: the EAT-Lancet Commission on healthy diets from sustainable food systems. Lancet. 2019;393(10170):447-92.

23. International Agency for Research on Cancer(IARC). IARC Monographs evaluate consumption of red meat and processed meat [Internet]. World Health Organization; 2015 [cited 2021 Mar 19]. Available from: https:// www.iarc.who.int/wp-content/uploads/2018/07/pr240_E.pdf.

24. World Cancer Research Fund (WCRF), American Institute for Cancer Research (AIRC). Continuous Update Project Expert Report 2018. Meat, fish and dairy products and the risk of cancer. Washington DC: AIRC; 2018.80 p.

25. Godfray HCJ, Aveyard P, Garnett T, Hall JW, Key TJ, Lorimer J, et al. Meat consumption, health, and the environment. Science. 2018;361(6399):1-8.

26. World Health Organization (WHO). Guideline: sodium intake for adults and children. Geneva: WHO; 2012. 56 p.

27. Mill JG, Malta DC, Nilson EAF, Machado ÍE, Jaime PC, Bernal RTI, et al. Fatores associados ao consumo de sal na população adulta brasileira: Pesquisa Nacional de Saúde. Cien Saude Colet. 2021;26(2):555-67.

28. Sarno F, Claro RM, Levy RB, Bandoni DH, Monteiro CA. Estimativa de consumo de sódio pela população brasileira, 2008-2009. Rev Saúde Públ. 2013;47(3):571-8.

29. Monteiro CA, Cannon G, Lawrence M, Louzada MDC, Pereira Machado P. Ultra-processed foods, diet quality, and health using the NOVA classification system. Rome: FAO; 2019. 49 p.

30. Souza AM, Souza BSN, Bezerra IN, Sichieri R. Impacto da redução do teor de sódio em alimentos processados no consumo de sódio no Brasil. Cad Saúde Pública. 2016;32(2):e00064615.

31. Nilson EA, Spaniol AM, Gonçalves VS, Moura I, Silva SA, L’Abbé $\mathrm{M}$, et al. Sodium reduction in processed foods in Brazil: analysis of food categories and voluntary targets from 2011 to 2017. Nutrients. 2017;9(7):742.

32. Huang T, Xu M, Lee A, Cho S, Qi L. Consumption of whole grains and cereal fiber and total and cause-specific mortality: prospective analysis of 367,442 individuals. BMC Med. 2015;13(1):1-9.

33. Li B, Zhang G, Tan M, Zhao L, Jin L, Tang X, et al. Consumption of whole grains in relation to mortality from all causes, cardiovascular disease, and diabetes: dose-response meta-analysis of prospective cohort studies. Medicine. 2016;95(33):1-9.

34. World Cancer Research Fund (WCRF), American Institute for Cancer Research. Continuous Update Project Expert Report 2018. Whole grains, vegetable and fruit and dairy products and the risk of cancer. Washington DC: AIRC; 2018. 140 p.
35. Silva DA, Rinaldi AEM, Azeredo CM. Clusters of risk behaviors for noncommunicable diseases in the Brazilian adult population. Int $\mathrm{J}$ Public Health. 2019;64(6):821-830.

36. Medina LPB, Barros MBDA, Sousa NFDS, Bastos TF, Lima MG, Szwarcwald CL. Desigualdades sociais no perfil de consumo de alimentos da população brasileira: Pesquisa Nacional de Saúde, 2013. Rev Bras Epidemiol. 2019;22(Supl 2):E190011.SUPL.2.

37. Ministério da Saúde (MS). Secretaria de Vigilância em Saúde. Departamento de Análise em Saúde e Vigilância de Doenças não Transmissíveis. Vigitel Brasil 2019: vigilância de fatores de risco e proteção para doenças crônicas por inquérito telefônico: estimativas sobre frequência e distribuição sociodemográfica de fatores de risco e proteção para doenças crônicas nas capitais de 26 estados brasileiros e no Distrito Federal em 2019. Brasília: MS; 2020. 132 p.

38. Assumpção DD, Domene SMÁ, Fisberg RM, Canesqui AM, Barros MBA. Differences between men and women in the quality of their diet: a study conducted on a population in Campinas, São Paulo, Brazil. Cien Saude Colet. 2017;22(2):347-58.

39. Lelis CT, Teixeira KMD, Silva NM. A inserção feminina no mercado de trabalho e suas implicações para os hábitos alimentares da mulher e de sua família. Saúde debate. 2012;36(95):523-32.

40. Szwarcwald CL, Montilla DER, Marques AP, Damacena GN, Almeida WS, Malta DC. Desigualdades na esperança de vida saudável por Unidades da Federação. Rev Saúde Públ. 2017;51(Supl 1):7s.

41. Lieffers JR, Ekwaru JP, Ohinmaa A, Veugelers PJ. The economic burden of not meeting food recommendations in Canada: the cost of doing nothing. PLoS One. 2018;13(4):e0196333.

42. Francisco PMSB, Assumpção DD, Borim FSA, Senicato C, Malta DC. Prevalência e coocorrência de fatores de risco modificáveis em adultos e idosos. Rev Saúde Públ. 2019;53:86.

43. World Health Organization (WHO). Global action plan for the prevention and control of noncommunicable diseases 2013-2020. Geneva: WHO; 2013. $103 \mathrm{p}$.

44. Instituto Brasileiro de Geografia e Estatística (IBGE). Objetivo 3 - saúde e bem-estar: assegurar uma vida saudável e promover o bem-estar para todos, em todas as idades [Internet]. IBGE; 2020 [cited 2021 Mar 23]. Available from: https://odsbrasil.gov.br/objetivo/objetivo?n=3.

45. Malta DC, Oliveira TP, Santos MAS, Andrade SSCA, Silva MMA. Avanços do plano de ações estratégicas para o enfrentamento das doenças crônicas não transmissíveis no Brasil, 2011-2015. Epidemiol Serv Saúde. 2016;25(2):373-90.

46. Viacava F, Bellido JwG. Condições de saúde, acesso a serviços e fontes de pagamento, segundo inquéritos domiciliares. Cien Saude Colet. 2016;21(2): 351-70.

47. Alves KPS, Jaime PC. A Política Nacional de Alimentação e Nutrição e seu diálogo com a Política Nacional de Segurança Alimentar e Nutricional. Cien Saude Colet. 2014;19(11):4331-40.

48. Malta DC, Reis AAC, Jaime PC, Morais Neto, OL, Silva MMA, Akerman M. O SUS e a Política Nacional de Promoção da Saúde: perspectiva resultados, avanços e desafios em tempos de crise. Cien Saude Colet. 2018;23(6):1799-809. 